\title{
Thrombotic vascular risk factors in inflammatory bowel disease
}

\author{
M Hudson, A Chitolie, R A Hutton, M S H Smith, R E Pounder, A J Wakefield
}

\begin{abstract}
Background-Thrombosis may be an important effector mechanism in the pathogenesis of Crohn's disease.

Methods-This study therefore investigated the prevalence of independent thrombotic risk factors (factor VII coagulant activity, lipoprotein (a), fibrinogen, plasma triglycerides, and smoking) in patients with Crohn's disease, ulcerative colitis, and normal controls.

Results-In Crohn's disease ( $n=75)$, the mean plasma VII:C, lipoprotein (a) and fibrinogen concentrations were significantly greater than in the normal population $(n=85)$. In ulcerative colitis $(n=35)$, only the mean factor VII:C concentration was significantly higher than normal. Ninety three per cent of patients with Crohn's disease and $86 \%$ of those with ulcerative colitis had at least one risk factor for thrombotic vascular disease, compared with $61 \%$ of the normal population (p<0.001).

Conclusions-In many young patients with inflammatory bowel disease, plasma concentrations of these prothrombotic factors were in excess of the limits that are regarded as posing an increased risk for the development of occlusive vascular disease.
\end{abstract}

(Gut 1996; 38: 733-737)

Keywords: inflammatory bowel disease, thrombosis.

Crohn's disease is associated with a granulomatous vasculitis and deposition of fibrin is a component of this inflammatory process. ${ }^{12} \mathrm{We}$ reported the presence of microthrombi in rectal biopsy specimens from patients presenting with either ulcerative colitis or Crohn's disease, which may be present even in macroscopically normal mucosa without histological inflammation. ${ }^{3}$ In addition, the incidence of systemic thromboembolic events in inflammatory bowel disease is reported to be higher than in the normal population, ${ }^{45}$ a finding that is reinforced by postmortem studies. ${ }^{6}$ The increased risk of thrombosis has been attributed to a hypercoagulable state, the nature of which has yet to be elucidated ${ }^{4-9}$ Despite evidence for activation of haemostasis in both Crohn's disease and ulcerative colitis, these conditions have been associated only rarely with a recognised primary abnormality of coagulation. ${ }^{78}$

Several independent risk factors for thrombotic vascular disease have been identified recently. ${ }^{9-11}$ Meade et al reported that high plasma factor VII coagulant activity (VII:C) is associated with an increased risk of an ischaemic myocardial event in male subjects over 40 years of age. ${ }^{9}$ In this study the mean plasma concentration of VII:C associated with an increased risk of a non-fatal myocardial event was $113 \mu / \mathrm{dl}$ (in men over 40 years of age). An increase in VII:C of one standard deviation above the mean was associated with a $62 \%$ increased risk of an episode of ischaemic heart disease within five years. VII:C is a measure of the state of functional activity of factor VII in plasma and has been shown to correlate with thrombin generation. ${ }^{10}$ Lipoprotein (a) ( $\mathrm{Lp}(\mathrm{a})$ ) concentrations greater than $300 \mathrm{mg} / \mathrm{l}$ are associated independently, with an increased risk of thrombotic vascular disease. Increased plasma fibrinogen and $\mathrm{Lp}(\mathrm{a})$ concentrations are also recognised risk factors for coronary artery and cerebrovascular disease. ${ }^{11} 12$ Smoking is an independent risk factor for both thrombotic vascular disease and Crohn's disease. ${ }^{13} 14$

The aim of this study was to compare the prevalence of these risk factors in healthy controls and in patients with Crohn's disease and ulcerative colitis, based upon the hypothesis that a systemic prothrombotic environment in Crohn's disease may aggravate intestinal microvascular inflammation, further compromising microcirculatory flow.

\section{Methods}

One hundred and ten patients were recruited consecutively from the inflammatory bowel disease clinic at the Royal Free Hampstead NHS Trust. Of the Crohn's disease patients, 26 were male and 49 female with mean (range) ages of $47(19-82)$ and $42(19-82)$ years, respectively. The ulcerative colitis patients included 22 men and 13 women with mean ages of 41 (16-77) and 49 23-77) years, respectively. These were compared with 85 apparently healthy subjects matched to the patient population for age and sex (38 males, 47 females) with mean ages of 43 (21-78) and 43 (20-75) years, respectively. All the normal controls were hospital workers. None had a history of ischaemic heart disease or diabetes mellitus. Details pertaining to smoking habit, active use of oral contraceptives, and hormone replacement therapy were obtained. All samples were obtained in the morning before mid-day and were non-fasting. The patients and healthy controls consented to the provision of blood samples for this study, which was approved by the ethical practices sub-committee of the Royal Free Hampstead NHS Trust.

All blood samples were taken in sodium citrate plastic tubes and plasma was separated 
TABLE I Thrombotic vascular risk factors in normal controls and patients with inflammatory bowel disease

\begin{tabular}{|c|c|c|c|c|c|}
\hline & $\begin{array}{l}\text { Age } \\
(y)\end{array}$ & $\begin{array}{l}\text { VII:C } \\
\text { (U/dl) }\end{array}$ & $\begin{array}{l}\text { Triglycerides } \\
(\mathrm{mmol} / \mathrm{l})\end{array}$ & $\begin{array}{l}\operatorname{Lp}(a) \\
(m g / l)\end{array}$ & $\begin{array}{l}\text { Fibrinogen } \\
(g / l)\end{array}$ \\
\hline \multicolumn{6}{|l|}{ Normal controls } \\
\hline Male $(n=38)$ & $43(17)$ & $95(22)$ & $1.3(0.9)$ & $127(5-641)$ & $2.5(0.8)$ \\
\hline $\begin{array}{c}\text { Female }(n=47) \\
\text { Crohn's disease }\end{array}$ & $42(16)$ & $105(23)$ & $1 \cdot 1(0 \cdot 8)$ & $126(1-842)$ & $3.0(0.9)$ \\
\hline \multicolumn{6}{|l|}{ Crohn's disease } \\
\hline Male $(n=26)$ & $47(21)$ & $121(33)^{\star \star \star}$ & $1 \cdot 2(0 \cdot 6)$ & $209(2-1051)$ & $3.4(0.9)^{\star \star \star}$ \\
\hline Female $(n=49)$ & 42 (17) & $134(43)^{\star \star \star}$ & $1.02(0.4)$ & $295(13-1289)^{\star \star \star}$ & $3.0(1.0)$ \\
\hline \multicolumn{6}{|l|}{ Ulcerative colitis } \\
\hline Male $(n=22)$ & $41(18)$ & $114(23)^{\star}$ & $1.6(0 \cdot 8)$ & $186(20-1012)$ & $2 \cdot 8(1 \cdot 0)$ \\
\hline Female $(n=13)$ & 49 (18) & $123(26)^{\star}$ & $1 \cdot 1(0 \cdot 5)$ & $104(0-933)$ & $2 \cdot 8(1 \cdot 1)$ \\
\hline
\end{tabular}

Student's $t$ test, $\mathrm{p}<0.05^{\star}, \mathrm{p}<0.001^{\star \star \star}$, compared with normal controls of same sex. Results presented as mean (SD) except for $\mathrm{Lp}(\mathrm{a})$, which is not normally distributed, median (range). Mann-Whitney $U$ test applied to $\mathrm{Lp}(\mathrm{a})$ data.

within 30 minutes of venepuncture. Plasma was obtained by double centrifuging $\times 2000 \mathrm{~g}$ for 20 minutes. Paired aliquots of plasma were snap frozen in liquid nitrogen or frozen at $-70^{\circ} \mathrm{C}$ until assay.

Crohn's disease clinical activity was based on the Harvey-Bradshaw score ${ }^{15}$; ulcerative colitis disease activity was based on sigmoidoscopic appearance, and was graded as either active or inactive.

\section{Assay procedures}

Plasma VII:C - the assay for VII:C is a one stage parallel line bioassay based on the prothrombin time. ${ }^{16}$ Reagents: factor VII-deficient plasma (Diagen, Manchester, UK), thromboplastin (rabbit brain, Diagen) diluted $1 / 20, \mathrm{CaCl}_{2} 25 \mathrm{mM}$, Owren's buffered saline, standard (immuno $100 \%$ reference plasma, Vienna, Austria). Three dilutions $(1 / 10,1 / 20$, and $1 / 40$ ) of standard and test plasma samples were made; $0.1 \mathrm{ml}$ of dilution, $0.1 \mathrm{ml}$ of diluted thromboplastin, and $0.1 \mathrm{ml}$ of factor VII deficient plasma were incubated together for two minutes. Then $0.1 \mathrm{ml}$ of $25 \mathrm{mM} \mathrm{CaCl}{ }_{2}$ was added and the clotting time measured using a KC10 coagulometer (Brownes, Theale, Reading, UK).

Plasma triglycerides - to examine the potential interaction of plasma triglyceride concentration with plasma VII:C concentration, ${ }^{17}$ the former was measured on each plasma sample, using an enzymic colorimetric test kit (Boehringer Mannheim, Lewes, UK).

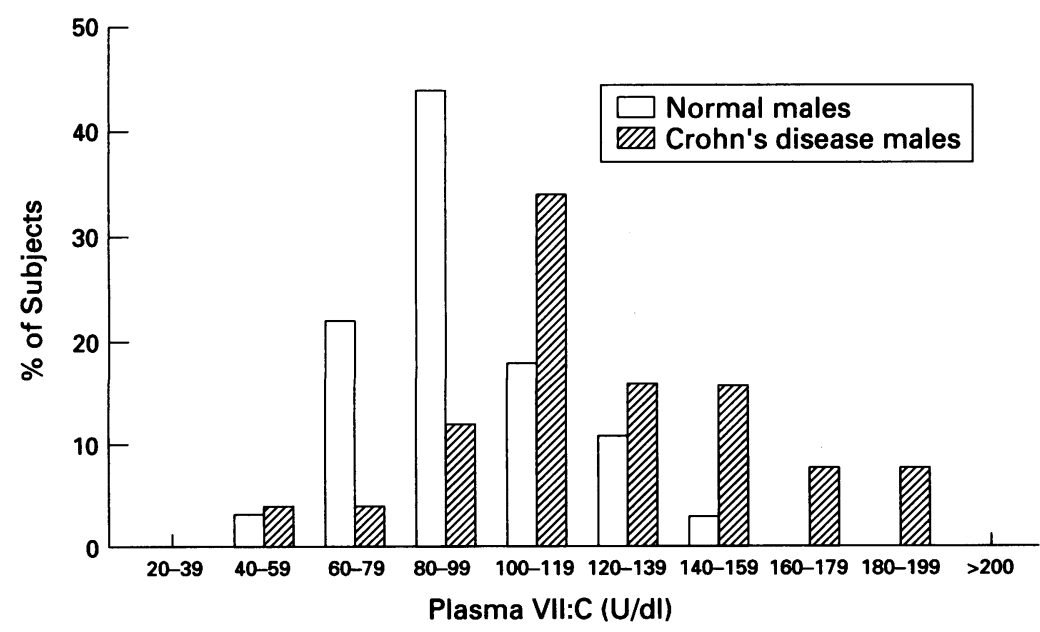

Figure 1: Distribution of VII:C in normal male controls and male patients with Crohn's disease. Normal controls $(n=38)$ Crohn's $(n=26) p<0: 001$.
Plasma fibrinogen concentration was measured by the Clauss method, ${ }^{18}$ using bovine thrombin (Brownes) and Owren's buffered saline.

Plasma $L p(a)$ concentration was measured by ELISA (Biopool, Cambridge, UK). To examine for potential antifibrinolytic activity of $\mathrm{LP}(\mathrm{a})$, fibrinolytic activity was measured by estimation of $\mathrm{d}$-dimer concentration by ELISA (Porton, Newmarket, UK). D-dimer is released from cross linked fibrin and is a sensitive marker of reactive fibrinolysis. ${ }^{19} 20$

$C$ reactive protein was measured in each patient with Crohn's disease as confirmation of disease activity.

\section{Results}

Concentrations of plasma VII:C were significantly higher in patients with either Crohn's disease or ulcerative colitis compared with the normal population (Table I). The greatest difference was seen in the Crohn's disease patients (Figs 1 and 2). Figure 3 shows a significant positive correlation between age and plasma VII:C concentration in both the healthy subjects and those with inflammatory bowel disease. The regression lines are almost parallel with the inflammatory bowel disease patients, at any age, having approximately a $20 \mathrm{U} / \mathrm{dl}$ increase in plasma VII:C compared with the normal subjects. In the Crohn's population VII:C did not correlate with disease activity determined by either the Harvey-Bradshaw score (Spearman, $p=0.97$ ) or the $\mathrm{C}$ reactive protein (Spearman, $p=0 \cdot 43$ ). Nor was there any significant correlation between VII:C and fibrinogen (Spearman, $p=0 \cdot 3$ ). There was no significant difference between VII:C in active and quiescent ulcerative colitis (Mann-Whitney $U$; $\mathrm{p}=0 \cdot 4)$. Smoking did not seem to affect VII:C concentrations (Table II). None of the inflammatory bowel disease patients was taking oral contraceptives, but one patient with Crohn's disease was receiving hormone replacement therapy. In the normal women the mean plasma VII:C concentration was not higher in those taking an oral contraceptive or hormone replacement therapy $(n=11$, mean (SD) 102 (30) U/dl) compared with the remainder $(\mathrm{n}=36,106(21) \mathrm{U} / \mathrm{dl})$.

There was no significant difference between the mean plasma triglyceride concentration in the patients with inflammatory bowel disease and the normal population (Table I). There was no significant correlation between the plasma concentrations of triglyceride and either VII:C, $\mathrm{Lp}(\mathrm{a})$ or fibrinogen concentration in the normal population (Spearman, $\mathrm{p}>0.05$ in all cases). In the female patients with Crohn's disease, however, the plasma triglyceride concentration correlated significantly with the plasma VII:C concentration (Spearman, $\mathrm{p}=0.05$ ).

Women with Crohn's disease had a mean $\mathrm{Lp}$ (a) concentration that was significantly increased compared with the normal population (Table I), but concentrations in male Crohn's patients, although higher than in the 


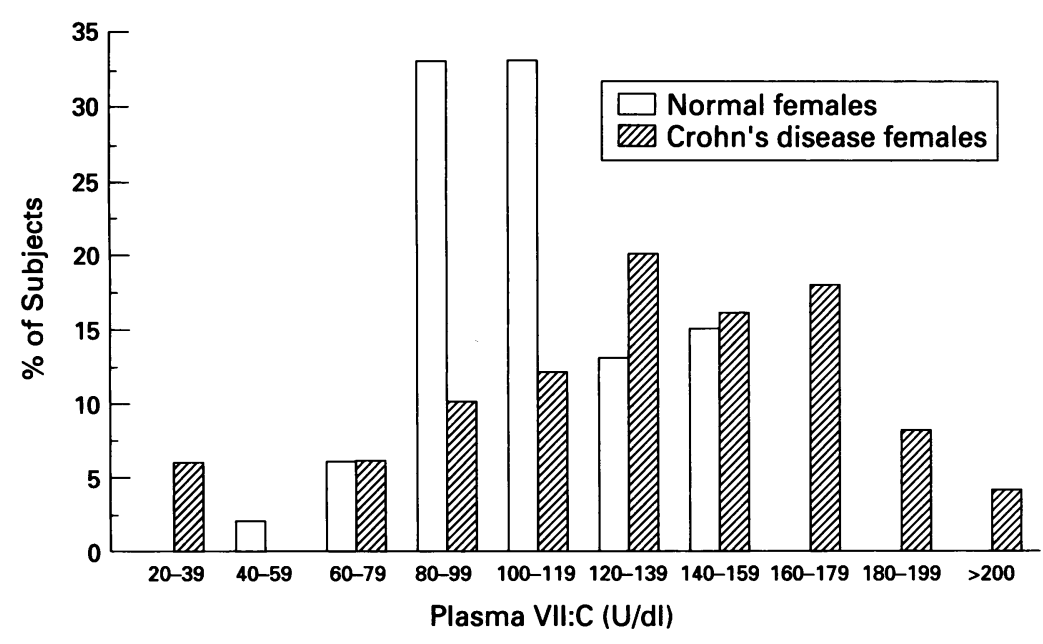

Figure 2: Distribution of VII:C in normal female controls and female patients with Crohn's disease. Normal controls $(n=47)$ Crohn's $(n=49) p<0 \cdot 001$.

normal population, did not reach significance $(p=0 \cdot 08)$. The plasma d-dimer concentration correlated significantly with clinical disease activity (Harvey-Bradshaw score) in the Crohn's patients (Spearman, $p=0.02$ ) but there was no significant inverse correlation with $L p(a)$ (Spearman, $p=0.5$ ).

This study identifies a large number of young patients with inflammatory bowel disease, with values of VII:C (Fig 3) and $\mathrm{Lp}(\mathrm{a})$ at or above proposed values of excess risk for thrombotic vascular disease (Table III).

The men with Crohn's disease had a significantly higher mean plasma fibrinogen concentration than the normal population (Table I). The fibrinogen concentration correlated significantly with clinical disease activity in Crohn's disease (Spearman, $p<0.001$ ) but there was no significant correlation with the acute phase peptide $\mathrm{C}$ reactive protein (Spearman, $\mathrm{p}=0.4$ ).

Overall, the overlapping pattern of independent risk factors for thrombosis in the study groups shows that $93 \%$ of the 75 patients with Crohn's disease and $86 \%$ of the 35 patients with ulcerative colitis had at least one increased independent risk factor for thrombotic vascular disease compared with $61 \%$ of the 85 normal subjects (Table III).

\section{Discussion}

The study shows that recognised risk factors for thrombotic vascular disease are significantly higher in patients with Crohn's disease or ulcerative colitis than the normal population. The most consistent abnormality was an increase in plasma VII:C concentrations, particularly in patients with Crohn's disease.

Increased concentrations of plasma VII:C might complicate microvascular damage and inflammation in the intestinal wall by augmenting focal fibrin deposition on the luminal surface of inflamed vessels. Miller et al showed that the concentration of VII:C in plasma correlates significantly with plasma prothrombin fragment $F 1+2$, a peptide cleaved from prothrombin by factor $\mathrm{Xa}$ during activated haemostasis. ${ }^{10}$ Factor VII is a potent procoagulant in the presence of tissue factor, an increased activity of which has been described ${ }^{8}$ and phenotypic expression shown in inflammatory bowel disease. ${ }^{21}$ In the presence of tissue factor the rate of factor $\mathrm{x}$ activation by factor VII is increased by up to 16000 -fold, thus increasing the potential rate of thrombin and fibrin production. ${ }^{22}$

There is no evidence that the plasma VII:C concentration is an acute phase reactant, ${ }^{23}$ and this is supported by the lack of correlation with either disease activity, $C$ reactive protein or fibrinogen in patients with Crohn's disease in this study. Although there is little that has been cited in published reports on VII:C in inflammatory disorders, a study in postoperative patients (non-inflammatory bowel disease) described a fall in plasma VII:C concentration after surgery. 23

There are reports that plasma VII:C concentration is influenced by the lipid content of the $\operatorname{diet}^{17}$ : in this study there was no correlation of VII:C with plasma triglycerides in the normal

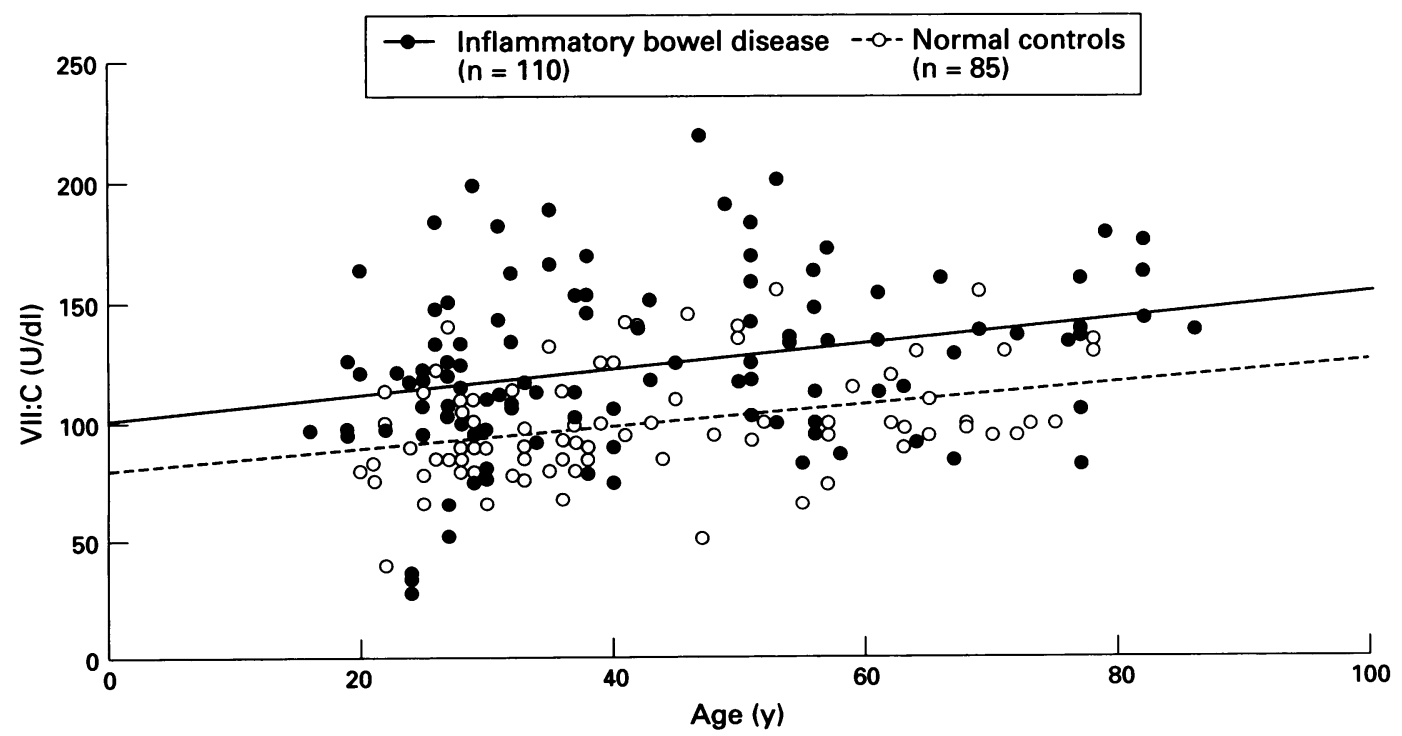

Figure 3: Factor VII:C correlates significantly with age in both the normal controls $(\mathrm{r}=0 \cdot 34, p<0 \cdot 05)$ and in the inflammatory bowel disease patients $(\mathrm{r}=0.3, p<0.05)$. The VII:C values are significantly higher in the inflammatory bowel disease patients at all age ranges. 
TABLE II Influence of smoking on VII:C and fibrinogen

\begin{tabular}{lcl}
\hline & VII:C (U/dl) & Fibrinogen $(g / l)$ \\
\hline Normal controls & & \\
$\quad$ Smokers $(\mathrm{n}=14)$ & $87(27)$ & $2 \cdot 7(0 \cdot 7)$ \\
$\quad$ Non-smokers $(\mathrm{n}=71)$ & $102(21)$ & $2 \cdot 7(0.9)$ \\
Crohn's disease & $115(37)$ & $3 \cdot 4(1.4)$ \\
Smokers $(\mathrm{n}=24)$ & $132(32)$ & $3.4(0.9)$ \\
\hline Non-smokers $(\mathrm{n}=23)$ & \\
\hline
\end{tabular}

None of the ulcerative colitis patients were smokers. Data presented as mean (SD).

male and female populations, although in the female Crohn's patients a significant correlation $(p<0.05)$ with VII:C was seen. Overall, however, there was no significant difference in plasma triglyceride concentrations between the normal population and the Crohn's disease patients.

It is possible that plasma VII:C concentration is increased in patients with inflammatory bowel disease by enhanced activation via the contact (intrinsic) system - that is, kinins and kininogens from the inflamed intestine activating factor XII and indirectly activating factor VII via factor IX. Should this be the case, the lack of correlation with clinical disease activity would suggest that this is an 'on-going' process, also activated during periods of apparent clinical remission. Alternatively there is evidence that plasma VII:C concentration may be genetically determined, ${ }^{24}$ and it is possible that this contributes to the recognised genetic risk that is associated with inflammatory bowel disease, a predisposition that has yet to be fully explained. 25

Although no conclusive evidence exists for the functional role of $\mathrm{Lp}(\mathrm{a})$ in atherosclerosis or other occlusive vascular disorders, there is abundant circumstantial evidence to link the two. $\mathrm{Lp}(\mathrm{a})$ has a structure closely related to low density lipoprotein, in that it consists of low density lipoprotein with an additional disulphide-linked apolipoprotein, apo (a). ${ }^{26}$ Apo (a) resembles plasminogen, the latter consisting of five different 'kringle' regions: apo (a) consists of kringle region 4 repeated between 13 and 37 times, and a kringle 5 subunit. It is the homology between the kringle 4 region that allows $\mathrm{Lp}$ (a) to compete with plasminogen for binding sites and potentially reduces the antithrombogenic nature of the vascular endothelium. ${ }^{27}$ Evidence from in vitro studies suggests that $\operatorname{Lp}(a)$ competes with, and binds preferentially to, plasminogen receptor binding sites on endothelial cells, ${ }^{28}$ this may impair local fibrinolytic processes and increase platelet accumulation. ${ }^{29}$ Although we found no correlation between systemic values of plasma

TABLE III Thrombotic risk factors in normal subjects and patients with inflammatory bowel disease

\begin{tabular}{llll}
\hline & $\begin{array}{l}\text { Normals } \\
(n=85)\end{array}$ & $\begin{array}{l}\text { Crohn's } \\
\text { disease } \\
(n=75)\end{array}$ & $\begin{array}{l}\text { Ulcerative } \\
\text { colitis } \\
(n=35)\end{array}$ \\
\hline VII:C $>113 \mathrm{U} / \mathrm{dl}(\%)$ & $21(24)$ & $49(66)$ & $20(57)$ \\
Lp(a) $>300 \mathrm{mg} /(\%)$ & $22(25)$ & $36(48)$ & $13(37)$ \\
Fibrinogen $>4 \mathrm{~g} / 1(\%)$ & $15(18)$ & $20(27)$ & $6(17)$ \\
Smoke (\%) & $19(21)$ & $24(32)$ & $0(0)$ \\
None of above (\%) & $33(39)$ & $5(7)^{\star \star \star}$ & $5(14)^{\star \star}$ \\
\hline$\chi^{2}$, compared with normal. & & \\
$\chi^{2}=22 \cdot 75, \mathrm{p}<0 \cdot 001^{\star \star \star}, \chi^{2}=6 \cdot 9, \mathrm{p}<0 \cdot 01^{\star \star}$.
\end{tabular}

d-dimers and $\mathrm{Lp}(\mathrm{a})$ in this study, this may not necessarily reflect what is happening in the intestinal microvasculature. There is evidence for impaired fibrinolysis in inflammatory bowel disease, including prolonged euglobulin lysis times and impaired release of t-plasminogen activator after venous occlusion. ${ }^{30} 31$ Plasma $\mathrm{Lp}$ (a) concentrations may also be determined genetically, ${ }^{32}$ and may contribute further to the genetic predisposition in Crohn's disease.

Fibrinogen is an acute phase protein, values of which increase with inflammation. High plasma fibrinogen concentrations increase plasma viscosity and activate platelets, ${ }^{33} 34$ both of which may compromise microcirculatory flow within the inflamed intestine.

Patients with Crohn's disease who smoke have more frequent relapses and a greater requirement for surgery. ${ }^{14}$ This may be explained in part by potentiation of an occlusive microvascular injury. Cigarette smoking has been shown to induce morphological injury to endothelial cells: this injury is associated with formation of microthrombi, impaired endothelial cell prostacyclin synthesis, and an increased aggregatory capacity for platelets. ${ }^{35}$ Furthermore, increased plasma fibrinogen concentrations, and decreased plasminogen and tissue plasminogen activator activity, were reported in habitual smokers. ${ }^{36}$ These findings may explain, at least in part, the increased risk of thrombotic vascular disease in smokers, and possibly the tendency for smoking to aggravate Crohn's disease. Table III emphasises that patients with both Crohn's disease and ulcerative colitis have a higher frequency of the above thrombotic risk factors than the normal subjects. Many of the patients have two or more of these risk factors, which can only aggravate microvascular inflammation.

It is of interest that none of the ulcerative colitis patients in the study were smokers, compared with one third of the Crohn's disease patients. It has been reported that smoking is protective in ulcerative colitis. ${ }^{37}$ This finding raises the question, 'Are the Crohn's disease patients requiring outpatient follow up because they smoke, and the ulcerative colitis patients because they do not?'. The potential importance of thrombosis in Crohn's disease and ulcerative colitis is supported further by the finding of Thompson et al that these diseases occurred significantly less frequently in haemophilia and von Willebrand's disease. ${ }^{38}$

The results of this study suggest that many patients with either Crohn's disease or ulcerative colitis are exposed to a procoagulant and potentially antifibrinolytic environment. To our knowledge there is no reported increased incidence of ischaemic heart disease in patients with inflammatory bowel disease. In a study by Talbot et $a l^{5}$ from the Mayo Clinic, however, 92 of $7199(1.3 \%)$ of patients studied between 1970 and 1980 developed thromboembolic complications. Of these seven developed cardiac thrombosis (fatal in five) and nine patients had cerebral thromboembolic complications in association with active bowel disease. It is difficult to discover if these events were directly attributable to the underlying inflammatory 
bowel disease because of other associated disease (age, obesity, diabetes, and atheroma). Disturbed haemostasis could actively compromise microcirculatory flow and aggravate any inflammatory vascular process within the intestinal wall. Such findings might help to explain the wide spectrum of disease activity, particularly in Crohn's disease, and present potential targets for therapeutic intervention.

Dr Mark Hudson was the Leslie Parrott Research Fellow supported by the National Association of Colitis and Crohn's ported by the National Association of Colitis and Crohn's Trust. The authors wish to thank Mr Dominic Byrne for measuring plasma triglyceride concentrations, Dr Christine Le (Director, Haemophilia Centre and Haemostasis Unit), the staff of the Haemophilia and Haemostasis Laboratory for their expert assistance.

1 Wakefield AJ, Sawyerr AM, Dhillon AP, Pittilo RM, Rowles PM, Lewis AAM, et al. Pathogenesis of Crohn's disease: multifocal gastrointestinal infarction. Lancet 1989; i: 1057-62.

2 Wakefield AJ, Sankey EA, Dhillon AP, Sawyerr AM, More $\mathrm{L}$ Sim R, et al. Granulomatous vasculitis in Crohn's disease. Gastroenterology 1991; 100: 1279-87.

3 Dhillon AP, Anthony A, Sim R, Wakefield AJ, Sankey EA Hudson $M$, et al. Mucosal capillary thrombi in rectal biopsies. Histopathology 1992; 21: 127-33.

4 Bargen JA, Barker NW. Extensive arterial and venous thrombosis complicating chronic ulcerative colitis. Arch Intern Med 1936; 58: 17-31

5 Talbot RW, Heppell J, Dozois RR, Beart RW. Vascular complications of inflammatory bowel disease. Mayo Clin Proc 1986; 61: 140-5.

6 Graef V, Baggenstoss AH, Sauer WG, Spittell JA. Venous thrombosis occuring with non-specific ulcerative colitis. Arch Intern Med 1966; 117: 277-82.

7 Hudson M, Hutton RA, Wakefield AJ, Sawyerr AM, Pounder RE. Evidence for activation of coagulation in Pounder RE. Evidence for activation of coagulation in

8 Edwards RL, Levine JB, Green R, Duffy M, Matthews E Brande W. Activation of blood coagulation in Crohn's disease. Gastroenterology 1987; 92: 329-37.

9 Meade TW, Mellows S, Brozovic M, Miller GJ, Chikrabarti HR, North WRS, et al. Haemostatic function and ischaemic heart disease: principal results of the Northwick Park heart study. Lancet 1996; ii: 533-7.

10 Miller GJ, Bauer KA, Wilkes HC, Meade TW. Plasma prothrombin fragment $F 1+2$ concentration is raised in men with an increased factor VII coagulant activity. $Q f \mathrm{Med}$ 1991; 80: 561-8.

11 Armstrong VW, Cremer P, Eberle E, Marke A, Schulze F, Weiland, et al. The association between serum $\mathrm{Lp}(\mathrm{a})$ concentrations and angiographically assessed coronary atherosclerosis. Atherosclerosis 1986; 62: 249-57.

12 Stone MC, Thorpe JM. Plasma fibrinogen - a major coronary risk factor. $\mathcal{F}$ Coll Gen Pract 1985; 35: 565-9.

13 Rabkin SW, Sackett DL. Arterial thromboembolism. Epidemiology. In: Colman RW, et al, eds. Haemostasis and thrombosis. Philadelphia: J B Lippincott, 1987: 1273-90.

14 Holdstock G, Savage D, Harman M, Wright R: should patients with inflammatory bowel disease smoke? $B M \mathcal{F}$ 1984; 288: 362

15 Harvey RF, Bradshaw JM. A simple index of Crohn's disease activity. Lancet 1980; i: 514 .

16 Dousan KWE. Appendix II. Techniques. In: Biggs $R$, Macfarlane RG, eds. Human blood coagulation. Haemostasis and Thrombosis. Oxford: Blackwell Scientific, 1972.
17 Miller GJ, Martin JC, Webster J, Wilkes H, Miller NE, Wilkinson WH, et al. Association between dietary fat intake and plasma factor VII coagulant activity - a predictor of cardiovascular mortality. Atherosclerosis 1986; 60: 269-77.

18 Clauss A. Gerinnungs physiologische Schnell method zur bestimmung des fibrinogens. Acta Haematol 1957; 17: $237-46$.

19 Rylatt DB, Blake AS, Cottis LE. An immunoassay for human D-dimer using mono 1983; 31: 767-78.

20 Rowbotham BJ, Carroll P, Whitaker AN, Bunce IH Measurement of cross-linked fibrin derivatives - use in the diagnosis of venous thrombosis. Thromb Haemost 1987; 57: 59-61.

21 More L, Sim R, Hudson M, Dhillon AP, Pounder RE Wakefield AJ. Immunohistochemical study of tissue factor expression in normal intestine and idiopathic inflammatory bowel disease. $\mathcal{F}$ Clin Pathol 1993; 46: 703-8.

22 Nemerson $Y$, Zur M, Bach R, Gentry R. The mechanism of action of tissue factor. In: Main KG, Taylor FB, eds. The regulation of coagulation. Developments in biochemistry. Vol regulation of coagulation. Developments in biochemistry. Vol

23 Hawkey CJ, Stirling Y, Chakrabarti R, Brozovic M, Cox AG, Meade TW. Haemostatic changes following surgery. Thromb Res 1983; 32: 223-7.

24 Lane A, Cruickshank JK, Mitchell J, Henderson A, Humphries S, Green F. Genetic and environmental determinants of factor VII coagulant activity in ethnic groups at differing risk of coronary heart disease. Atherosclerosis 1992; 94: 43-50.

25 Orholm M, Iselius L, Sorensen TIA, Munkholm P, Langholz $\mathrm{E}$, Binder $\mathrm{V}$. Investigation of inheritance of chronic inflammatory bowel disease by complex segregation analysis. $B M F$ 1993; 306: 20-4.

26 Rhoads GG, Dahlem G, Berg K, Morton NE, Dannenberg AL. $L p(a)$ lipoprotein as a risk factor for myocardial infarction. $₹ A M A$ 1986; 256: 2540-4.

27 Scanu AM, Fless GM. Lipoprotein (a): Heterogeneity and biological relevance. $\mathcal{F}$ Clin Invest 1990; 85: 1709-15.

28 Hajjar KA, Gavish D, Breslow JL, Nachman RL Lipoprotein (a) modulation of endothelial cell surface fibrinolysis and its potential role in atherosclerosis. Nature 1989; 339: 303-5.

29 Miles LA, Plow EF. Lp(a): an interloper in the fibrinolytic system. Thromb Haemost 1990; 63: 331-5.

30 Conlan MG, Haire WD, Burnett DA. Prothrombotic bnormalities in inflammatory bowel disease. Dig Dis $S c i$ 1989; 34: 1089-93.

31 Gris JC, Schved JF, Raffanel C, Dubois A. Impaired fibrinolytic capacity in patients with inflammatory bowel disease. Thromb Haemost 1990; 63: 472-5.

32 Utermann G, Menzel HJ, Kraft HG, Duba HC, Kemmler HG, Seitz C. Lp(a) glycoprotein phenoptypes. Inheritance and relation to $\mathrm{Lp}(\mathrm{a})$-lipoprotein concentrations in plasma. $\mathcal{F}$ Clin Invest 1987; 80: 458-65.

33 Meade TW, Vickers MV, Thompson SG, Seghaatchian MJ. The effect of physiological levels of fibrinogen on platelet aggregation. Thromb Res 1985; 38: 527-34.

34 Lowe GDO, Drummond MM, Lorimer AR, Hutton I Forbes CD, Prentice CRM, et al. Relation between extent of coronary artery disease and blood viscosity. $B M \mathcal{F} 1980$; i: 673-4.

35 Pittilo RM, Macklin IJ, Rowles PM, Machin SJ, Woolf N. Effects of cigarette smoking on the ultrastructure of the thoracic aorta and its ability to produce prostacyclin. Thromb Haemost 1982; 48: 173-6.

36 Bull HA, Pitillo RM, Woolf N, Machin SJ. The effect of nicotine on human endothelial cell release of prostaglandins and ultrastructure. $B r f$ Exp Pathol 1988; 69: 413-21.

37 Osborne MJ, Stansby GP. Cigarette smoking and its relationship to inflammatory bowel disease: a review. $\mathcal{f} R$ Soc Med 1992; 85: 214-5.

38 Thompson NP, Wakefield AJ, Pounder RE. Inherited disorders of coagulation appear to protect against inflammatory bowel disease. Gastroenterology 1995; 108: 1011-5. 